\title{
Medico-legal evidence collection in child sexual assault cases: a forensic significance
}

\author{
Suminder Kaur ${ }^{{ }^{*} \mathbb{D}}$, Simarpreet Kaur ${ }^{2}$ and Banita Rawat ${ }^{1}$
}

\begin{abstract}
Background: Every year, millions of children face sexual exploitation worldwide. In India, 109 children (National Crime Records Bureau2018) were sexually abused everyday (22\% jump from the previous year). Even with advanced DNA techniques, the conviction rate remains low. The methods used for forensic DNA evidence analysis vary around the world, but the primary step of biological evidence collection plays the most vital role. Proper and timely evidence collection from the victim by a trained medical professional is important.

Main body: Dynamics of child sexual assault being massively different from an adult rape demands altogether different approach of evidence collection. A standard sexual kit employed for evidence collection needs urgent modifications considering genital development of pre- and post-pubertal victims. In the present study, parameters including systemic collection and evaluation of forensic evidences, medico-legal examination, and developmental consequences of sexual assault on pre-pubertal victims were assessed. Further suggestions for separate evidence collection kit during medico-legal examination were given for pre-pubertal victims and alleged accused in sexual assault cases in order to streamline and for better evaluation of DNA analysis in forensic laboratories.

Conclusion: The importance of expert medical practitioners plays a significant role in collection of appropriate information and evidences from the victim of sexual assault. General guidelines for evidence collection in sexual assault cases are not well suited for pre-pubertal victims. Appropriate reforms pertaining to the age and genital development of victims are required. Securing clothing as forensic evidence is essential in most cases as it turned out to be the exclusive evidence bearing material. The purpose of this article is to bring awareness about the thorough medical examination and modified sexual assault kit for pre-pubertal victims and alleged accused for a better approach in evidence collection and conviction rate.
\end{abstract}

Keywords: Pre-pubertal victim, Sexual assault kit, Medico-legal, Evidence collection

\section{Background}

One of the most heinous crimes faced by humanity is sexual assault. A lot has been done in the forensic scientific field to aid in the conviction of the perpetrator of the crime. With passing years, the ultimate focus has been on systematic collection of evidence from proper documentation to reconstruction of crime in order to aid in the prosecution. Upon reporting such crimes, medico-legal

\footnotetext{
*Correspondence: ksuminder@gmail.com

1 DNA Fingerprinting Unit, Biology Division, Regional Forensic Science

Laboratory, Chanakyapuri, New Delhi, India

Full list of author information is available at the end of the article
}

examination is done for which sexual assault evidence collection kits are used for the collection of biological evidences. Considering the possible transfer of biological secretions in sexual assault cases, sexual assault kits along with forensic DNA evidence catalyze verification of the assault and identification of the offender (Peterson et al., 2012). In the past few years, a steep rise in the number of sexual assault offenses/cases against children has been seen. In the Indian subcontinent, "Asian Centre for Human Rights" reported 48,338 cases of child sexual abuse from 2001 to 2011. Keeping this in view, a separate law, the Protection of Children from Sexual Offences (POCSO) Act 2012, has been enacted in India 
since November 2012 to prevent children below 18 years of age from sexual offenses (Kaur et al., 2019). A separate law for sexual offenses against children must be strengthened with the introduction of a separate mechanism of evidence collection from the girl victims and alleged accused.

\section{Main text}

Children are most vulnerable to sexual abuse due to their mental immaturity and incapability to defend themselves. The nature of child sexual abuse differs largely from the sexual assault of an adult. There may or may not be any physical injuries or ejaculation of semen (Christian et al., 2000; Kairys et al., 1999). Child abuse cannot be handled in the same way as in post-pubertal victims because immediate disclosure is quite rare in young children following the event. The hesitancy to report abuse is due to threats made by the perpetrator. Accidental disclosure is more common in children below 10 years after a complaint of pain in the abdomen or genital parts or a bloodstain in the underwear (Kaur et al., 2019; Kairys et al., 1999). Child sexual abuse should rather be seen as a process and not just a single episode (Kaur et al., 2019). Moreover, young children may not cooperate in the collection of vaginal, anal, or oral swabs, especially after a painful episode of assault (Kairys et al., 1999). Hence, evaluation protocol similar to that acclaimed for postpubertal victims may prove inappropriate for pre-pubertal victims.

\section{Forensic considerations for evidence collection and preservation}

Collection and evaluation of forensic evidence along with genital examination are the most important constituents of the medical assessment in reported sexual assault cases. It requires extensive knowledge to document the history and conduct medico-legal examination in order to verify the commitment of crime as well as factors that might mimic sexual assault. In cases of sexual assault, the most important biological and DNA evidence is seminal fluid. During the assault, semen may get deposited in the vagina but may drain to the anal region and also to the clothing and bedding of the victim (Burg et al., 2011). Not just semen, there can be other biological evidences such as pubic hair, body fluids, and skin cells present on the body or clothes of the child victim that can be a potential source of the DNA profile of the accused. In case of hand-genital contact or in cases of struggle between the child victims and accused, fingernails of the victim may contain skin cells of the accused (Burg et al., 2011). These biological evidences, if collected, preserved, and analyzed properly and timely, can provide a DNA profile of the accused and hence aids in the conviction (Burg et al.,
2011; Forr et al., 2018; Makasa \& Heathfield, 2018). The DNA profile of the accused can be obtained from the vaginal swabs even after a long time interval depending on the post-assault activity of the victim and forever on dried clothes (Burg et al., 2011; Forr et al., 2018; Makasa \& Heathfield, 2018). There are reports where children reported hand-genital contact, yet the semen was detected on the vaginal swabs collected from the victim (Christian et al., 2000). Thus, evidence collection should not be totally based on the child's narrative of the assault. Transfer of biological evidence is a two-way process; hence, the swabs and clothes of the accused need to be collected for the presence of blood or other body cells/ fluids of the victim to obtain a DNA profile. Samples collected timely and properly may become unfit for the analysis if they are not packed, preserved, and stored properly before the analysis (Butler, 2012; Kaur et al., 2020).

Most Indian forensic laboratories use standard sexual assault kit for female victims of all age groups that mostly includes breast swab, body fluid collection, anal swab, oral swab, vaginal secretions (swab and smear), cervical mucus collection and smear, combing/cutting of pubic hair, fingernail cuttings, dental floss and toothpick, and blood and urine samples which are best suited for female victims that have attained puberty. The limitation is some samples like cervical mucus collection, pubic hair (combing and cutting), and breast swabs are irrelevant in the case of pre-pubertal child victims. Hence, some modifications in evidence collection from a pre-pubertal child are strictly needed. A standard system (sexual maturity rating) must be used to judge the physical development of the victim, using five stages (from preadolescent to adult) based on the degree of development of secondary sexual characteristics during puberty. Tanner staging is the standard method to categorize pubertal stages of development; stage 1 indicates pre-pubertal genital development, while stage 5 infers adult genital development (Niec, 2002). This would permit the medical professional to gauge the degree of pubertal maturation that has occurred. Sexual assault kits should not only be based on age and gender of the victim but also on relevant evidence collection from the alleged accused. The victim's DNA profile found on the accused exhibits can help conclude the results even if no male DNA was detected on the victim's exhibits. Further incomplete evidence collection such as lack of nail clippings from alleged accused in case of vaginal fingering along with the victim's evidence proves futile as there are little/no chances of getting DNA from the victim's exhibits as compared to alleged accused nail clippings. This inability to give any conclusive DNA results due to the lack of vital evidence collection from pre-pubertal victims has led the author to propose this study. The approach of different kits with 
relevant evidence components both from the victim and the alleged accused will certainly permit a better and a much effective approach towards the collection and DNA analysis, finally leading to better prosecution. This study will not only help child victims but society at large will also be benefitted from it.

\section{Examination of pre-pubertal child victim}

One important aspect while assessing the victim is to determine their ability to testify the assault by taking into account the factors like child's memory, recognition of people, consistency-continuity of thought, affectivity conditions, and ability to report the presence of any psychological symptoms. Since the evaluation and reliability of the testimony in case of an underage victim are often questionable, Argo Antonina et al. suggested various projective psychological tests that could help to classify any mental disorders manifested by the victim by assessing the subject's personality structure (Argo \& Triolo, 2012).

Upon reporting, interviewing of the child victim, to obtain details of an assault, should preferably be conducted by a trained professional possessing the knowledge of the nature and the consequences of sexual abuse (Kairys et al., 1999). Medical examination should be conducted by pediatric medical personnel who should address the health care needs of child victims and also promote healing of the victims. The medical examiner should begin the examination by obtaining consents, documentation of biographical information, history, details of the assault, and the time between the assault and the evaluation. They must also carry out a timely collection of appropriate evidence. In case of child assault, consent could be obtained from the parents or the accompanying guardian (Savino \& Turvey, 2011; Tozzo et al., 2018).

Medical officials are often not familiar with the genital anatomy in non-abused children and therefore expect to find signs of injury in accordance with the child's narrative of the incidence (Adams, 2018). A multi-method evaluation strategy, therefore, would be an effective tool in the examination of the pre-pubertal victims that includes an examination using supine labial parting, supine labial traction, and one in the prone knee-chest position. Boyle et al. have demonstrated the importance of this sort of examination, especially for hymenal injuries, both acute or in the past (Hariton, 2012; Smith et al., 2018). The time since the assault and a history of blood following the episode are the two best factors indicating abnormal findings and are quite significant. Child sexual assault (CSA) cases that lack physical evidence do not confirm or refuse sexual abuse, so misleading statements should be avoided for transparency in case reporting. Understanding of histology and the anatomy of the pre-pubertal genitalia is essentially required particularly if there is a history of bleeding and genital pain at the time of the incidence or signs of genital healing after forceful penetration (Hariton, 2012).

Another common form of sexual abuse against prepubertal children is oral sex, the edges of the mouth and oral cavity must be inspected for injuries to the palate, gums, teeth, pharynx, and frenula (Savino \& Turvey, 2011). It is important to note that not every sexual contact will result in physical trauma. In cases where the penis is placed between the children's thighs or labia, no apparent trauma was seen with regard to the hymen, and therefore, normal exam findings are there in such cases (Makasa \& Heathfield, 2018). Examination of the buttocks, perianal skin, and anal folds for injury, foreign materials, and other findings such as any bleeding signs, contusions, tearing, and bruising should be noted and documented with appropriate anatomical diagrams (Savino \& Turvey, 2011).

Resulting from the assault, genital injuries could possibly prove to be a piece of a larger picture of the dynamics of the assault to support the claims of sexual assault and help in the decision-making. Factors like the type of sexual activity, delayed disclosure, and natural healing of the hymen may suggest acute genital examinations (Gallion et al., 2016). As revealed in earlier studies, child victims who were examined acutely were more likely to have significant genital findings than victims examined weeks or months following the last incidence of sexual abuse. In an examination by Berenson et al., the median time span from the last incidence of assault was 42 days, and they revealed that fewer than $5 \%$ of 3- to 8-year-old female victims assessed had findings diagnostic to the assault. The study from Heppenstall-Heger et al. indicated that about $14.6 \%$ of female victims having acute genital injuries had persistent anatomic changes. In another study, upon acute evaluation, $73 \%$ of the child victims revealed diagnostic genital findings. It is possible that most of their genital injuries would have healed, if they were evaluated after a certain time span, except for cases with hymenal transections (Gallion et al., 2016).

Colposcopic examination and other alternate resources can be used when injuries are not seen by the naked eye examination in order to increase the sensitivity and specificity of medical assessment (Kotzé \& Brits, 2019). These photographs/videos can also serve as a piece of evidence later for jurisdiction. Sometimes, the presence of sexually transmitted infections (STI) like Neisseria gonorrhoeae or Chlamydia trachomatis among pediatric victims can be due to abusive contact, so prompt evaluation of STI helps to determine sexual abuse (Bechtel, 2010). 


\section{Effective parameters for potential DNA findings}

Currently, DNA profiling is the method for the identification of accused in cases of sexual offenses provided that the sample/evidence collection and preservation has been done timely and appropriately. Corroborative DNA evidence and medical examination along with a confession from the accused increase the likelihood of prosecution. The timely reporting of the assault and examination increases the success of the recovery of forensic evidence. It has been observed that during child sexual assault, the most frequently found biological evidence is the blood of the victim/blood mixed with seminal fluid. Studies showed that poorly preserved blood samples lead to the generation of either partial or no DNA profile. Therefore, strict guidelines must be followed during sample collection (Kaur et al., 2020). Medico-legal examination and collection of potential evidence play a very important role in the findings of DNA profiling. It would be best to avoid invasive examination methods as they may mimic that of abuse. Medical examination should be conducted by an examiner with strong foundation/knowledge of normal genital anatomy and injuries and someone who can build up the confidence of the victim so that the child cooperates in evidence collection (Kairys et al., 1999; Forr et al., 2018).

Studies suggest that sexually abused children examined within $72 \mathrm{~h}$ following the assault are more likely to have distinguishable biological/DNA evidence thereafter can be missed because of the prompt healing nature of superficial mucosal injury (Christian et al., 2000). Even then, the expert examiner must look for the injuries (the children may not be able to recollect the last event of abuse) to help corroborate their version of events (Savino \& Turvey, 2011). Ideally, three key strategies are used for genital examination: direct visualization, staining techniques to highlight injuries, and colposcopic examination (Sommers, 2007). In the Indian subcontinent, the use of staining techniques and colposcopy for medical assessment is not prevalent yet. Hymenal status and overall examination of the genitalia are thought to be enough for the purpose, which does not yield much significant information apparently (Herrmann et al., 2014). With the increasing child abuse cases, there rises an urgent need to upgrade the techniques and resources being used. Also, an expert child psychologist should always be present along with the child victims before and during the medical examination. With reference to the kits employed for the purpose, it has been seen that in the Indian subcontinent, a single kit is used for sexual assault cases regardless of the gender and age of the victims. A standard differential sexual assault kit for pre-pubertal child victims could help in preventing chaos and unnecessary torture during the process of examination and collection. Medical examiners may misjudge the importance of clothing as a useful source, but it can turn out to be the exclusive evidence bearing material. Helen et al. emphasized the need to recover clothing from the victims as there are chances of getting a complete DNA profile despite multiple washing of the victim's clothes (Brayley-Morris et al., 2015). Properly and timely collected samples should be packed, sealed, and stored as per recommendations to increase the potential of DNA evidence. The suggested procedure and evidence can help in the standardization of examination and collection of evidence in sexual assault kits for pre-pubertal child victims of sexual assault.

\section{Conclusions}

Sexual abuse involving penetration is likely to cause physical injury to the genitals. The corroborative clinical findings among such child victims are of utmost importance that can be solved by collecting appropriate evidence during medical examinations. During forensic case reporting, the medical assessment plays a significant role in supporting the child victim and family, safeguarding their health and well-being and providing information to the judicial systems. In case of pre-pubertal victims, a medical practitioner who is well versed with the anatomy and psychology of young victims particularly a pediatric gynecologist should be preferred. Due to the clandestine nature of the crime, the evidence collection should be done as soon as possible. It is advised that adolescence involves a time stretch during which teenagers are at varied stages of pubertal development, suitable reforms must be made in evidence collection kits with regard to the age and genital development of the victim involved. Also, a separate kit for the alleged accused including all the vital evidences for biological case reporting is an indispensable tool. If there is not much advantage, exposing child victims to tests involving uncomfortable processes must be avoided. Swabbing of the anus, genitals, and throat can be evaded in case of recently traumatized victims. Only relevant swabs can be collected after easing the mental and physical pain of the child victims. Colposcopy has been proven extensively beneficial over the conventional techniques of genital examination. Therefore, both colposcopic examination and staining techniques can be made the routine procedures in the medical evaluation of sexual assault victims particularly for genital injuries.

CSA is known to be associated with significant psychological problems, making it increasingly imperative to develop evaluation protocols. Apart from medical assessment, it is equally crucial to make a psychological evaluation in child protection issues to ensure the child's health and welfare (Malhotra \& Biswas, 2006). The evaluation may focus on rehabilitation intended 
to safeguard the child and help the family. This study thus suggests that CSA examiners should be well versed with the recommendations and guidelines on medical and psychological evaluation of CSA victims in order to provide a more reliable and purposeful interpretation of medical findings (Adams et al., 2016). Recent research also indicates a steep increase in sexual assault among minority groups such as lesbian, gay, bisexual, and queer students thereby suggesting a need for their primary prevention (Eisenberg et al., 2021).

In the present scenario, telemedicine can be employed in case of a lack of expert clinicians in the CSA medical evaluation. It involves the exchange of medical information between a clinician and patient using video conferencing software as well as educate the families and cater the needs of CSA victims and adolescents.(Stavas et al., 2018) Moreover, an approach should be adopted to offer emotional support, crisis intervention, education, and advocacy to children and their caregivers. Coordination across disciplines and agencies in society and across jurisdictions in some instances is crucial to simultaneously address the health, legal, safety, and support goals. Such efforts could perhaps aid a better managing of child victims as well as safeguard their legal rights.(A national protocol for sexual abuse medical forensic examinations pediatrics, 2018)

\section{Abbreviations}

POCSO: Protection of Children from Sexual Offences; CSA: Child sexual assault; STI: Sexually transmitted infections; DNA: Deoxyribonucleic acid.

\section{Acknowledgements}

The authors are thankful to Ms. Deepa Verma, director, Forensic Science Laboratory, Delhi, India, and K.C. Varshney, Incharge, Regional Forensic Science Laboratory, Chanakyapuri, New Delhi, for their unconditional and valuable support during the entire study. A special thanks to Dr. Vineeta Saini, faculty, Department of Forensic Science, SGT University, Gurugram, and Rakesh Sharma, laboratory assistant, for their support.

\section{Authors' contributions}

The original concept and design of the study are formulated by SK. The drafting is initiated by SPK while writing portions are done by BR. SPK and SK conducted the retrieval of the literature. The reviewing and final revision of the draft are done by all three authors. The overall coordination and writing are supervised under SK's guidance. All the authors have read and approved the final manuscript.

\section{Authors' information}

Suminder Kaur, PhD, is a Senior Forensic/Chemical Examiner (Biology/DNA) at the Regional Forensic Science Laboratory at Chanakyapuri, New Delhi. Her area of research mainly focuses on factors affecting child sexual assault victims by exploring the evidences collected from the crime scene, medico-legal examination, and DNA analysis besides assessing the socioeconomic and psychological conditions of both victim and alleged accused. Her other areas include developing a modified DNA isolation protocol for highly degraded exhibits pertaining to sexual assault kits.

Simar Khurana, Masters in Forensic Sciences, Amity University, worked as a summer trainee at Regional Forensic Science Laboratory at New Delhi. Her main area of interest includes social and DNA challenges faced by child sexual assault victims aged up to 10 years and offenders (particularly juveniles). Banita Rawat, Masters in Forensic Sciences, National Institute of Criminology \& Forensic Sciences, is presently working as a senior scientific assistant at Regional Forensic Science Laboratory New Delhi. Her main area of interest includes exploring better/modified protocols in CSA and murder cases starting from exhibits collected from the crime scene, preservation techniques, and DNA isolation protocols.

\section{Funding}

This research did not receive any specific grant from funding agencies in the public, commercial, or not-for-profit sectors.

Availability of data and materials

Not applicable

\section{Declarations}

Ethics approval and consent to participate

Not applicable

\section{Consent for publication}

Not applicable

\section{Competing interests}

The authors declare that they have no competing interests.

\section{Author details}

${ }^{1}$ DNA Fingerprinting Unit, Biology Division, Regional Forensic Science Laboratory, Chanakyapuri, New Delhi, India. ${ }^{2}$ Amity University, Noida, Uttar Pradesh, India.

Received: 15 July 2021 Accepted: 22 November 2021

Published online: 01 December 2021

\section{References}

A national protocol for sexual abuse medical forensic examinations pediatrics; U.S. Department of Justice Office on Violence Against Women (2018).

Adams JA (2018) Understanding medical findings in child sexual abuse: an update for 2018. Acad Forensic Pathol. https://doi.org/10.1177/19253 62118821491

Adams JA et al (2016) Updated guidelines for the medical assessment and care of children who may have been sexually abused. J Pediatr Adolesc Gynecol. https://doi.org/10.1016/j.jpag.2015.01.007

Argo A, Triolo V (2012) Validity and credibility of a child's testimony of sexual abuse: a case report. EuroMediterranean Biomed J 2012. https://doi.org/ 10.3269/1970-5492.2012.7.21

Bechtel K (2010) Sexual abuse and sexually transmitted infections in children and adolescents. Curr Opin Pediatr 22(1):94-99. https://doi.org/10.1097/ MOP.0b013e32833502ad

Brayley-Morris H, Sorrell A, Revoir AP, Meakin GE, Court DS, Morgan RM (2015) Persistence of DNA from laundered semen stains: implications for child sex trafficking cases. Forensic Sci Int Genet. https://doi.org/10.1016/j. fsigen.2015.07.016

Burg A, Kahn R, Welch K (2011) DNA testing of sexual assault evidence: the laboratory perspective. J Forensic Nurs. https://doi.org/10.1111/j.19393938.2011.01111.x

Butler JM (2012) Advanced topics in forensic DNA typing: methodology

Christian CW, Lavelle JM, De Jong AR, Loiselle J, Brenner L, Joffe M (2000) Forensic evidence findings in prepubertal victims of sexual assault. Pediatrics. https://doi.org/10.1542/peds.106.1.100

Eisenberg ME, Lust K, Mathiason MA, Porta CM (2021) Sexual assault, sexual orientation and reporting among college students. J Interpersonal Violence 36(1-2):62-82. https://doi.org/10.1177/0886260517726414

Forr C, Schei B, Stene LE, Ormstad K, Hagemann CT (2018) Factors associated with trace evidence analyses and DNA findings among police reported cases of rape. Forensic Sci Int. https://doi.org/10.1016/j.forsciint.2017.12 025 
Gallion HR, Milam LJ, Littrell LL (2016) Genital findings in cases of child sexual abuse: genital vs vaginal penetration. J Pediatr Adolesc Gynecol. https:// doi.org/10.1016/j.jpag.2016.05.001

Hariton TN (2012) Sexual assault in prepubertal it: girls is normal to be normal or is it? Evidence of vaginal penetration in prepubertal girls. Med Sci Law. https://doi.org/10.1258/msl.2012.012015

Herrmann B, Banaschak S, Csorba R, Navratil F, Dettmeyer R (2014) Physical examination in child sexual abuse - approaches and current evidence. Dtsch Arztebl Int. https://doi.org/10.3238/arztebl.2014.0692

Kairys SW et al (1999) Guidelines for the evaluation of sexual abuse of children: subject review. Pediatrics. https://doi.org/10.1542/peds.103.1.186

Kaur S, Kaur S, Varshney K (2019) Recent trends in child rape crisis in Delhi (India): a forensic overview. Forensic Sci Int Reports. https://doi.org/10. 1016/j.fsir.2019.100047

Kaur S, Saini V, Dalal R (2020) UV-visible spectroscopic effect on haemoglobin \& DNA degradation: a forensic approach. Forensic Sci Int. https://doi.org/ 10.1016/j.forsciint.2019.110078

Kotzé JM, Brits H (2019) Child sexual abuse: the significance of the history and testifying on non-confirmatory findings. Afr J Prim Heal Care Fam Med 11, no. 1. https://doi.org/10.4102/phcfm.v11i1.1954

Makasa I, Heathfield LJ (2018) A retrospective study of sexual offences in Zambia. J Forensic Legal Med. https://doi.org/10.1016/j.jfm.2017.12.009

Malhotra S, Biswas P (2006) Behavioral and psychological assessment of child sexual abuse in clinical practice. Int J Behav Consult Ther. https://doi.org/ $10.1037 /$ h0100764

Niec A (2002) Forensic issues in the assessment of sexually assaulted adolescents. Paediatr Child Health (Oxford). https://doi.org/10.1093/pch/7.3.153

J. Peterson, D. Johnson, D. Herz, L. Graziano, and T. Oehler(2012) "Sexual assault kit backlog study," Final grant Rep.

Savino J, Turvey B (2011) Rape investigation handbook

Smith TD, Raman SR, Madigan S, Waldman J, Shouldice M (2018) Anogenital findings in 3569 pediatric examinations for sexual abuse/assault. J Pediatr Adolesc Gynecol. https://doi.org/10.1016/j.jpag.2017.10.006

Sommers MS (2007) Defining patterns of genital injury from sexual assault: a review. Trauma Violence Abuse. https://doi.org/10.1177/1524838007 303194

Tozzo P, Ponzan, O E, Spigarolo G, Nespeca P, Caenazzo L (2018) Collecting sexual assault history and forensic evidence from adult women in the emergency department: a retrospective study. BMC Health Serv Res. https://doi.org/10.1186/s12913-018-3205-8

N Stavas, J Shea, S Keddem, J Wood, W Orji, C Cullen, P Scribano (2018), "Perceptions of caregivers and adolescents of the use of telemedicine for the child sexual abuse examination". Child Abuse Negl. 85 47-57; doi:https:// doi.org/10.1016/j.chiabu.2018.08.009

\section{Publisher's Note}

Springer Nature remains neutral with regard to jurisdictional claims in published maps and institutional affiliations.

\section{Submit your manuscript to a SpringerOpen ${ }^{\circ}$ journal and benefit from:}

- Convenient online submission

- Rigorous peer review

- Open access: articles freely available online

- High visibility within the field

- Retaining the copyright to your article

Submit your next manuscript at $\boldsymbol{\nabla}$ springeropen.com 